\title{
EL USO DEL AGUA EN LOS JARDINES DE LAS URBANIZACIONES DEL LITORAL DE ALICANTE. PRÁCTICAS DE AHORRO Y SUS CAUSAS ${ }^{1}$
}

\author{
Álvaro Francisco Morote Seguido \\ Instituto Interuniversitario de Geografía. Universidad de Alicante \\ alvaro.morote@ua.es
}

\section{RESUMEN}

El intenso proceso de urbanización que ha vivido la costa mediterránea española con la instalación de la actividad turística ha llevado consigo una serie de repercusiones territoriales. Una de ellas ha sido el incremento del consumo de agua gracias al aumento de la urbanización de baja densidad caracterizada por la presencia de nuevas naturalezas urbanas como son jardines y piscinas. Esta investigación tiene como objetivo conocer y analizar el uso del agua en el exterior de los hogares de las urbanizaciones del litoral de Alicante. La metodología llevada a cabo ha consistido en la realización de diferentes entrevistas a los propietarios de estas viviendas, para de esta manera, conocer de primera mano el uso que hacen del recurso hídrico en el exterior de la vivienda. La principal conclusión extraída ha sido que los residentes han adoptado en los últimos años diferentes estrategias y cambios en el uso del agua en los espacios ajardinados con el objetivo de reducir el consumo de agua.

Palabras clave: jardín; urbanización; agua; consumo; Alicante.

\section{ABSTRACT}

Water use in the gardens of the residential developments on the coast of Alicante. Water-saving practices and their causes

The intensive urbanization process experienced by the Spanish Mediterranean coast in relationship with tourist activity has brought some changes in land use. One of these has been the increase in water consumption due to the expansion of urban sprawl characterized by the presence of urban natures, such as gardens and pools. The aim of this study is to know and analyse water use in the outdoor areas of the dwellings in the residential developments of the Alicante coast. The methodology implemented has been the conducting of interviews with the owners in order to understand water use in outdoor areas. The main conclusion was that residents had adopted several strategies and changes in recent years in the use of water in outdoor areas with the aim of reducing water consumption.

Key words: garden; urbanization; water; consumption; Alicante.

\section{INTRODUCCIÓN}

El litoral mediterráneo español ha vivido grandes transformaciones territoriales desde los años sesenta y setenta del pasado siglo con la instalación de la actividad turística (Vera, 2006; Hernández, 2013). Algunas de estas transformaciones ha sido el intenso proceso de urbanización que ha repercutido en un especta-

\footnotetext{
1 Este artículo es resultado de la concesión de una beca pre-doctoral de Formación de Profesorado Universitario del Programa Nacional de Investigación Científica, Desarrollo e Innovación Tecnológica (FPU) y se inserta en en los proyectos de investigación "Urbanización y metabolismo hídrico en el litoral de Alicante: análisis de tendencias para el periodo 2000-2010" (CSO2012-36997-CO2-02) y "Usos y gestión de recursos hídricos no convencionales en el litoral de las regiones de Valencia y Murcia como estrategía de adaptación a la sequía" (CSO2015-65182-C2-2-P), ambos financiados por el Ministerio de Ciencia y Tecnología".
} 
cular incremento del número de viviendas y población en la franja costera (Burriel, 2008; Piqueras, 2012). Estos cambios no sólo se han sucedido en el litoral mediterráneo español (Del Romero, 2008), sino que también se han generalizado en el mediterráneo europeo como, por ejemplo, Francia (Fernández y Barrado, 2011), Italia (Salvati y Sabbi, 2011) o áreas urbano-turísticas de los Estados Unidos de Norte América (Deoreo y Mayer, 2012) o Australia (Loh y Coghlan, 2003; Troy y Holloway, 2004). En vinculación con este proceso urbano, una de las repercusiones más evidentes ha sido el incremento del consumo de agua (Molina, et al., 2004; Gössling, 2015). Ello se relaciona directamente con el modelo urbano predominante, basado en la urbanización extensiva imitando el modelo anglo-sajón (Wentz y Gober, 2007).

La urbanización de baja densidad se caracteriza por la presencia de viviendas unifamiliares con jardín y piscina (Mayer, et al., 1999; Morote, Saurí y Hernández, 2016). En este sentido, la existencia de estas naturalezas urbanas en el exterior de los hogares han sido las causantes, de que en estas tipologías, el consumo de agua doméstico sea mayor que en otras (Morote, 2014). Este modelo urbano de ciudad-jardín y el modelo de bienestar individual transmiten unos valores que pueden repercutir en conductas poco responsables en torno al uso del agua (García, 2013). Se suceden, en el peor de los casos, auténticos paisajes urbanos donde los espacios ajardinados se convierten en escenarios donde se da un "hidrofetichismo" encaminado a mostrar una distinción social con el objetivo de cumplir unas normas sociales establecidas entre los residentes de la urbanización (Askew y McGuirk, 2004). Numerosos estudios ponen de manifiesto la importancia del agua consumida en el exterior de la vivienda (Yabiku, Casagrande y Farley-Metzger, 2008; Mustafa, Smucker, Ginn, Johns y Connely, 2010). Por ejemplo, en el caso de Australia, Hurd (2006) llegó a la conclusión de que el riego del jardín supone más de 50\% del total del agua consumida en el hogar. También destacan trabajos en el caso español, en torno a la urbanización y el consumo de agua como, por ejemplo, en el Área Metropolitana de Barcelona (Domene y Saurí, 2006), Girona (García, 2014; Padullés, Vila y Barriocanal, 2014a; 2014b; 2016) o el litoral de Alicante (Rico, 2007; Morote y Hernández, 2014; Morote, 2015).

La creciente preocupación sobre la disponibilidad de agua en cantidad y calidad suficiente ha convertido en urgente la necesidad de avanzar hacia un enfoque de sostenibilidad en la planificación y la gestión de los recursos hídricos (García, 2013). También cabe indicar que en los últimos años se ha constatado empíricamente un descenso del consumo de agua doméstico (Saurí, 2003; March y Saurí, 2014; Gil, et al., 2015). Este descenso se debe por una amalgama de causas múltiples e interrelacionadas: la mejora de la eficiencia del suministro, la instalación de dispositivos de ahorro en el hogar, la presencia de electrométricos que usan agua más eficientemente, una mayor sensibilización ambiental, el uso de aguas regeneradas depuradas y pluviales, el incremento del precio del agua, cambios socio-económicos, la actual crisis económica y las condiciones climáticas. Son numerosos los cambios y estrategias llevados a cabo por los propietarios con la finalidad de reducir el consumo de agua, tal y como ponen de manifiesto en la costa alicantina Morote y Hernández $(2014 ; 2016)$ como ha sido reducir la vegetación atlántica por la mediterránea y la pavimentación de las áreas ajardinadas, todo ello con el objetivo de reducir el consumo de agua y el recibo de la factura del agua. Ello se debe al incremento del monto pagado en los últimos años, un aumento del 77\% en tan sólo una década en el caso de la ciudad de Alicante (Gil, et al., 2015).

\section{OBJETIVOS Y METODOLOGÍA}

El objetivo de esta investigación es conocer y analizar el uso del agua en los jardines de las urbanizaciones del litoral de Alicante e identificar cuáles son las prácticas de ahorro que han implementado los residentes de estas viviendas y analizar cuáles han sido las causas que han motivado la adopción de estas medidas. Metodológicamente, para obtener la información necesaria para este estudio, se llevaron a cabo diferentes entrevistas a los propietarios de las viviendas de las urbanizaciones de la costa de Alicante.

Las entrevistas realizadas forman parte del proyecto "Urbanización y metabolismo hídrico en el litoral de Alicante: análisis de tendencias para el periodo 2000-2010" (CSO2012-36997-CO2-02) financiado por el Ministerio de Ciencia y Tecnología, donde participaron el Instituto Interuniversitario de Geografía de la Universidad de Alicante, el Instituto de Medio Ambiente de la Universidad de Girona y el Departamento de Geografía de la Universidad Autónoma de Barcelona.

Las entrevistas se realizaron entre los meses de mayo y julio de 2011 a los propietarios de viviendas de diferentes urbanizaciones del litoral de Alicante, diferenciando entre la costa norte (Calpe, Altea, Polop, La Nucía y l'Alfàs del Pi) y costa sur (San Fulgencio, Rojales, Torrevieja y San Miguel de Salinas) (Figura 1). Se eligieron estas localidades ya que son representativas de las tipologías urbano-turísticas que carac- 
terizan al área de estudio donde predomina la urbanización extensiva de chalés. Con respecto a las entrevistas realizadas, su número fue también distribuido en torno a la población total de cada municipio y de la urbanización seleccionada. Se obtuvo una ratio de éxito de un 30\%, es decir, para las 130 entrevistas realizadas, se llevaron a cabo unos 430 intentos. De esas 130 entrevistas, se desestimaron 8 por motivos varios (incompletas, errores en los valores indicados, etc.).

Figura 1. Área de estudio

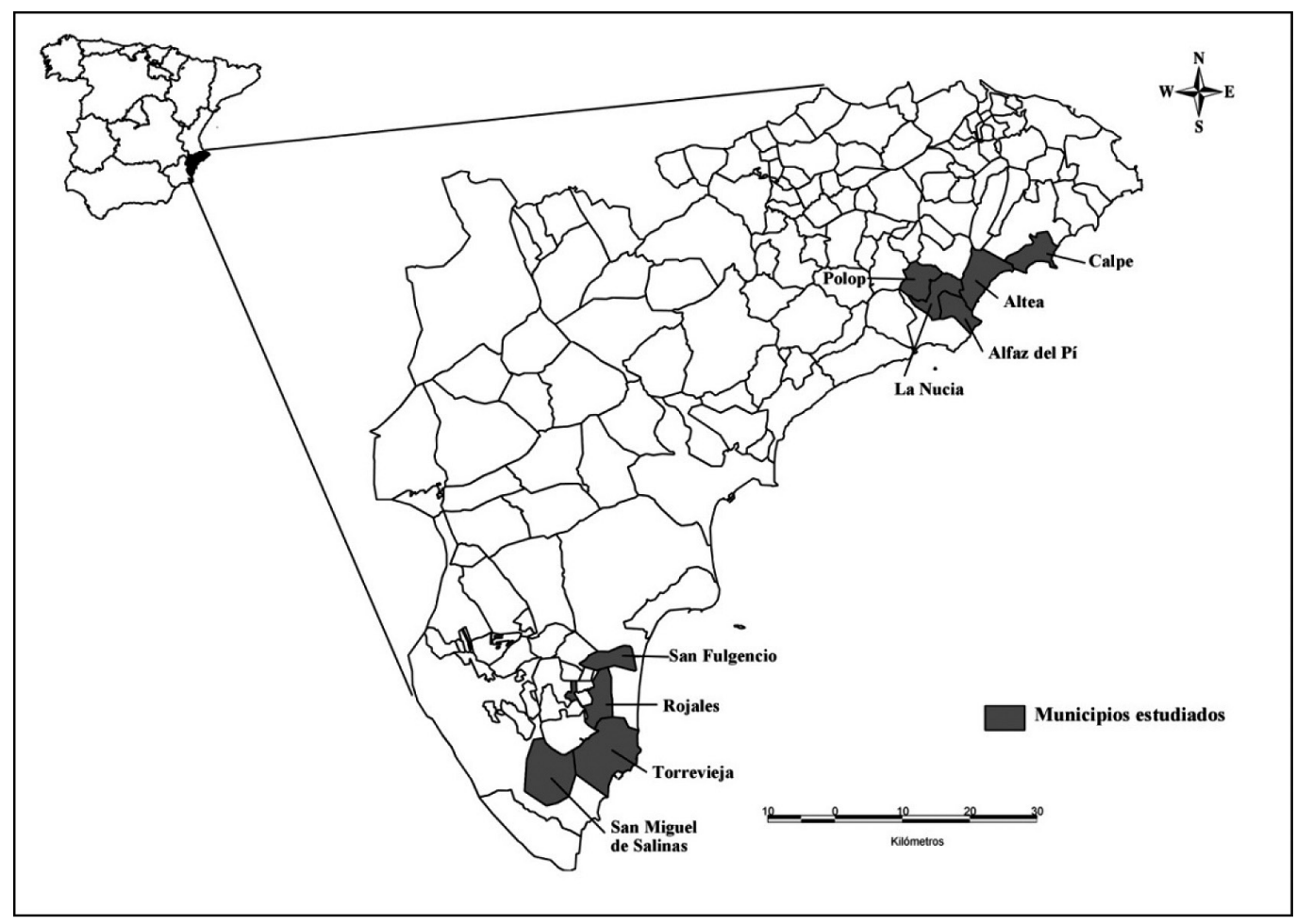

Elaboración propia.

La entrevista se estructuró en 6 grandes apartados. El primero de ellos recoge información sobre los aspectos generales de la persona entrevistada y de los residentes del hogar (edad, sexo, país de nacimiento, años que lleva viviendo en el municipio y en la vivienda, estado socio-laboral y el nivel educativo). El segundo contiene información sobre las características del hogar (antigüedad del hogar, régimen de tenencia, la forma de su adquisición, tipo de ocupación y la frecuencia de uso en el caso de ser una hogar destinado a segunda residencia), mientras que el tercero se relaciona con el exterior de la vivienda (presencia de piscina, superficie ocupada por los diferentes elementos que se encuentran en el exterior -patio, jardín, huerto, etc.-, fuente de abastecimiento de agua que se utiliza para las diferentes partes del hogar, y si ha habido algún cambio importante en el exterior de la vivienda). El cuarto se vincula con las características del jardín (tipología y densidad de vegetación, y método de riego). El quinto recoge información sobre las variables de comportamiento de los residentes del hogar en torno al uso del agua. Finalmente, en el apartado sexto se obtuvieron datos de consumo de agua con el objetivo de conocer el nivel de renta de cada hogar, los comportamientos reales del agua y recoger el número suficiente de datos de consumo para poder construir un año completo de datos.

Para esta investigación se han escogido los resultados obtenidos en el Apartado 1 (para de esta manera, introducir y conocer las características socio-económicas de los residentes de las urbanizaciones), y la información obtenida del Apartado 5, "Variables de comportamiento". Con ello se pretende conocer qué hábitos y comportamientos tienen los residentes de los hogares de estas urbanizaciones en torno al uso del agua y en especial, relacionado con el jardín. En el Apartado 5 se diferenciaron 5 variables con 4 preguntas cada una (Tabla 2). Cada una de estas preguntas se podía contestar en una escala numérica entre 1 y 5: 1 (completamente en desacuerdo), 2 (en desacuerdo), 3 (neutral), 4 (de acuerdo), 5 (fuertemente de acuerdo). 
Tabla 1. Recuento de entrevistas realizadas en las urbanizaciones del área de estudio

\begin{tabular}{|c|c|c|}
\hline & Urbanización & $\mathrm{N}^{\mathrm{o}}$ \\
\hline \multirow{5}{*}{ Calpe } & Cuxarret & 4 \\
\hline & Les Cucarres & 5 \\
\hline & Cometas & 3 \\
\hline & Cometas 1 & 1 \\
\hline & Cometas 2 & 2 \\
\hline \multirow{4}{*}{ Altea } & Horizonte & 4 \\
\hline & Miramar & 6 \\
\hline & Montagut & 1 \\
\hline & Tossal del Molar & 4 \\
\hline Polop & Ladera Ponoig & 5 \\
\hline La Nucía & Montebello & 5 \\
\hline \multirow{4}{*}{ l'Alfàs del Pi } & Escandinavia & 6 \\
\hline & San Rafael & 7 \\
\hline & Jardín de Alfaz & 5 \\
\hline & Barranco Honda & 3 \\
\hline San Fulgencio & Finca la Vega & 5 \\
\hline \multirow{4}{*}{ Rojales } & Pueblo Lucero & 7 \\
\hline & Golf Country & 3 \\
\hline & Ciudad Quesada & 2 \\
\hline & Doña Pepa & 3 \\
\hline \multirow{4}{*}{ Torrevieja } & Loma Laguna & 6 \\
\hline & La Siesta & 6 \\
\hline & Doña Inés & 6 \\
\hline & Los Balcones & 6 \\
\hline \multirow{4}{*}{ San Miguel de Salinas } & La Balsa & 3 \\
\hline & Lago Azul & 3 \\
\hline & Blue Lagoon & 4 \\
\hline & Eagle Nest & 7 \\
\hline Total & Total & 122 \\
\hline
\end{tabular}

Elaboración propia.

Tabla 2. Preguntas realizadas a los entrevistados en el Apartado 5 de la entrevista (Variables de comportamiento)

\begin{tabular}{|l|}
\hline 1. Estilo de vida: la importancia del espacio verde en el hogar y el vecindario \\
\hline Encuentro muy agradable que haya parques y jardines públicos en mi barrio \\
\hline No me gusta tener un jardín con vegetación exuberante \\
\hline Nunca he querido tener macetas \\
\hline Para mí es muy importante la presencia de plantas en mi hogar \\
\hline 2. La recreación en el jardín: la importancia del jardín como una fuente de ocio y de entretenimiento \\
\hline Me proporciona gran satisfacción dedicarme al jardín \\
\hline La jardinería es una pérdida de tiempo \\
\hline Cuidar mi jardín es una manera agradable de romper con mi rutina \\
\hline No me gusta la jardinería \\
\hline 3. Interés en el jardín: el disfrute de la jardinería como una actividad \\
\hline Me gusta enseñar mi jardín a mis amigos y familiares \\
\hline Paso buenos ratos en mi jardín \\
\hline Los que viven en esta casa nunca hacen uso del jardín \\
\hline La parte exterior de la vivienda es un lugar ideal para hacer cenas o comidas \\
\hline 4. Actitudes en torno al ahorro y uso del agua \\
\hline Ahorrar agua requiere un esfuerzo que no merece la pena \\
\hline El agua del grifo es un recurso demasiado valioso para ser desperdiciado \\
\hline No cambiaría mi estilo de vida por ahorrar algo de agua \\
\hline Ahorrar agua es un deber que se tiene que cumplir incluso cuando no se está en situación de sequía \\
\hline
\end{tabular}




\begin{tabular}{|l|}
\hline 5. Hábitos de los usos del agua en el hogar, tanto en el interior como en el exterior \\
\hline Cuando debo comprar plantas para mi jardín, siempre tengo en cuenta que no se tengan que regar mucho \\
\hline Cuando me ducho cierro el grifo mientras me enjabono \\
\hline Riego las plantas a primera hora de la mañana o a última de la noche \\
\hline A menudo utilizo la lavadora cuando no está llena \\
\hline
\end{tabular}

Elaboración propia.

\section{RESULTADOS}

\subsection{Perfil socio-económico de los residentes}

Los resultados obtenidos en vinculación con los rasgos personales tienen como objetivo poner de manifiesto el perfil socio-económico de los residentes. En este sentido, sexo, edad, nacionalidad, situación socio-laboral y nivel educativo ayudaran a relacionar los resultados obtenidos en el apartado de las variables de comportamiento. La mayoría de las personas entrevistadas han sido hombres (el 71,43\%). La entrevista la realizaba la primera persona que salía al encuentro con los entrevistadores, que por lo general han sido hombres que estaban en el exterior del hogar realizando tareas de mantenimiento y riego de las zonas ajardinadas. En relación con la nacionalidad, la más destacada es la británica (40,53\% del total de los entrevistados). En segundo lugar se encuentra la española, pero con unas cifras muy inferiores (el $25,33 \%$ ). En tercer lugar destacan los alemanes (el 12,16\%), holandeses (el 7,09\%), noruegos (el 3,04\%), belgas, suizos e italianos (el 2,03\% respectivamente) y otros (5,78\%) (Figura 2 ).

Figura 2. Nacionalidad de los entrevistados

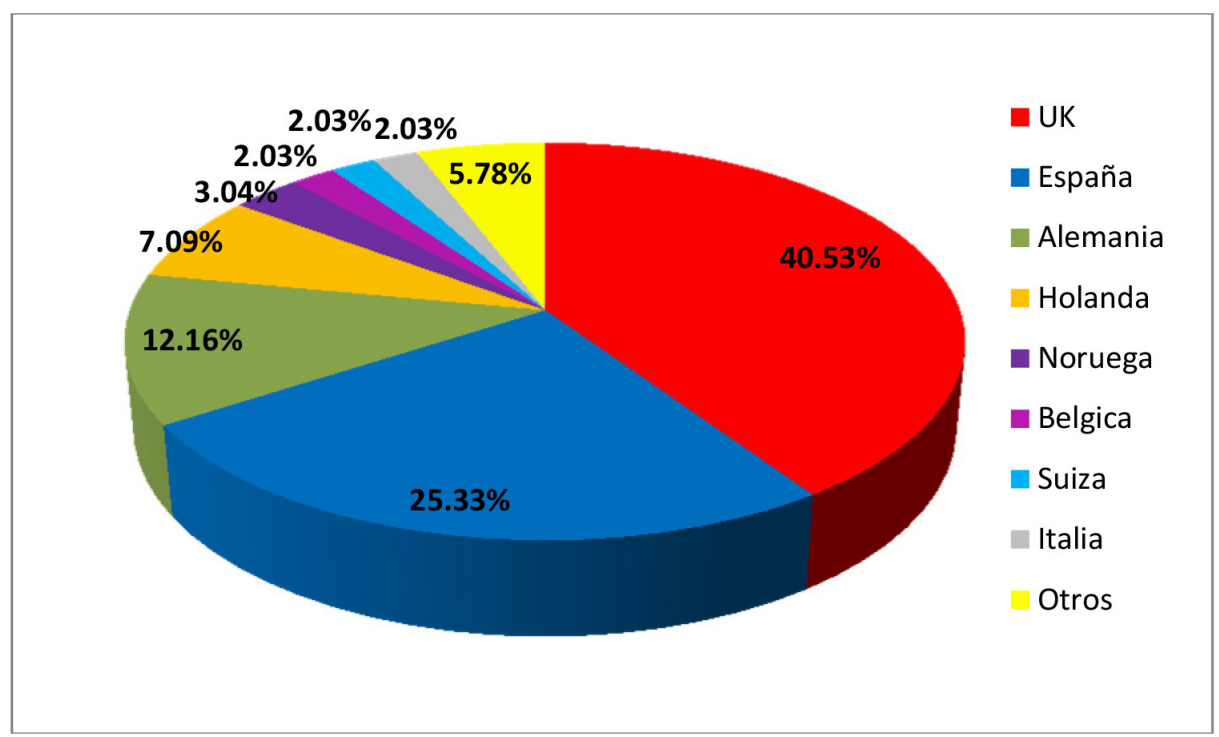

Fuente: Resultados de las entrevistas. Elaboración propia.

El análisis de los datos relativos a la edad de los entrevistados pone de manifiesto el predominio de personas de 60 años o más. Éstos representan el 65\% del total, mientras que con edades inferiores se encuentran los entrevistados entre 25 y 59 años (el 35\%). Estos datos vienen a corroborar la presencia mayoritaria de personas mayores extranjeras (jubilados o prejubilados) en estas áreas residenciales. Por tanto, hay presencia de una población que ha establecido su vivienda (tanto primera como segunda residencia) en el litoral de Alicante, bien coincidiendo con el inicio de las actividades turísticas en los años sesenta o bien con posterioridad (último boom inmobiliario) con un particular incremento a partir de 2001. Si se analizan estos mismos datos en función de la nacionalidad, el porcentaje de personas entrevistadas con 60 años o más, es superior al de 25-59 años, principalmente para la población extranjera. Para el caso de la nacionalidad británica, el 74\% tiene 60 años o más, los alemanes el $77 \%$, los holandeses el 63\%, los noruegos el $50 \%$ y para el resto de nacionalidades extranjeras el $77 \%$. En cambio, con los españoles 
ocurre lo contrario. En este sentido, el 61\% de los españoles entrevistados tienen una edad entre 25-59 años (Figura 3). De los datos de los extranjeros, cabe destacar que muchos de ellos a pesar de tener una edad inferior a los 60 años, ya estaban prejubilados, es decir en una edad comprendida entre los 50 y 60 años. Por otro lado como se ha mencionado, los españoles son los únicos que tienen el porcentaje menor de 60 años o más, es decir, se encuentran en edad de trabajar. Residen en estas zonas pero lo hacen por motivos laborales o por haber elegido esta tipología urbana frente a otras más compactas y en núcleos urbanos tradicionales y no como la mayoría del resto de los extranjeros que establecen aquí su vivienda para residir una vez se han jubilado (Casado, 2012).

En relación con la situación socio-laboral, siguiendo la lógica de datos anteriores, al ser una población mayoritariamente con 60 años o más, el 55,47\% de todos los habitantes son jubilados, mientras que el $26,78 \%$ trabaja (principalmente población española), el 14,04\% estudia y sólo un 3,7\% está en situación de desempleo. Si se tiene en cuenta el nivel educativo de los entrevistados destaca la alta cualificación de la población seleccionada. Tienen el título de Educación Secundaria (Bachillerato Elemental, Bachillerato Superior, BUP, Bachillerato LOGSE, COU, PREU, FP de grado medio, FPI, Oficialía Industrial o equivalente, FP de grado superior) el 52,36\%, y con estudios universitarios (Diplomatura, Arquitectura o Ingenierías Técnicas, Licenciatura, Ingenierías o Doctorado) el 27,58\%. Luego, con datos inferiores se encuentran los que no tienen ningún nivel educativo y con Educación Primaria el 10,03\% respectivamente. Con estos datos, se puede deducir que hay presencia de una población muy formada, y con poder adquisitivo medio; medio-alto, ya que si son jubilados con alta formación, está indicando que tuvieron la posibilidad de estudiar cuando eran jóvenes, y por consiguiente, posteriormente un trabajo bien remunerado.

Figura 3. Edad de los entrevistados por nacionalidad

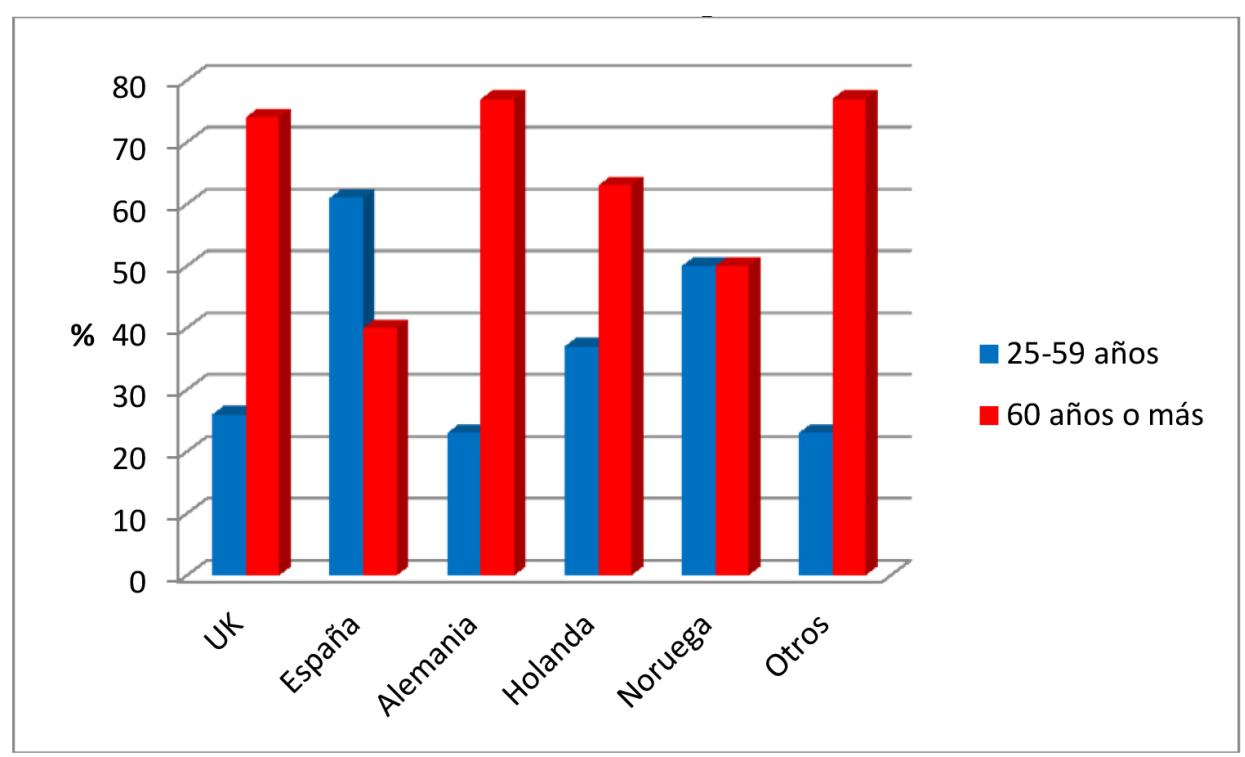

Fuente: Resultados de las entrevistas. Elaboración propia.

Relevante resulta asimismo, relacionar nacionalidad y nivel de formación. Así pues, hay una población altamente cualificada, que corresponde con la población extranjera, y con un poder adquisitivo alto, y por otro lado, una población con cualificación baja que corresponde con los españoles, ya que éstos representan el $50 \%$ de los entrevistados sin nivel educativo. La segunda nacionalidad que se observa que no tiene tampoco ningún nivel de estudios es la británica (el 30\%), mientras que el resto (el 20\%) se distribuye con porcentajes bajos entre el resto de las nacionalidades (alemanes, holandeses, belgas, etc.). En relación con las personas entrevistadas que afirmaron tener Educación Primaria, destaca igualmente la población española con el 45,37\% y los británicos con el 30\%, mientras que no hay una tercera nacionalidad a destacar. Cabe explicar que si aparece en estos datos la población británica es por el alto porcentaje de personas entrevistadas de esta nacionalidad (no hay que olvidar que representaban el 40,53\% del total de las personas que realizaron la entrevista). Con Educación Secundaria, el porcentaje de españoles empieza a disminuir, y en cambio, cobran protagonismo otras nacionalidades como la británica o la alemana. 
Los españoles en este caso representan el 17,54\%, los británicos el 49,20\% y los alemanes el 15,73\%. Con estudios universitarios destacan nuevamente los británicos con el 33,37\%, mientras que los españoles en esta ocasión ascienden al 26,65\% (españoles con poder adquisitivo medio-alto) y aparece la nacionalidad holandesa que representa el 13,33\%. También resulta ilustrativo analizar los datos anteriores en función de la edad. Por ejemplo, para el caso de las personas entrevistadas que tienen Educación Secundaria y Universitaria, el 71,60\% tiene 60 años o más, y además, la principal nacionalidad que se encuentra en este rango de edad y que destaca por su alta cualificación es la británica con el 74,30\%.

\subsection{Uso del agua y medidas de ahorro en el jardín y en el hogar}

\subsubsection{Estilo de vida: la importancia del espacio verde en el hogar y en el vecindario}

El primer cuestionario del apartado de las variables de comportamiento se relacionaba con la importancia de los espacios verdes en el hogar y en el vecindario. Se ha hecho mención a preguntas sobre la satisfacción ante la presencia de zonas verdes en el barrio, la presencia de un jardín con vegetación exuberante, la tenencia de macetas en el jardín y la importancia de tener plantas en el hogar (Tabla 3).

Tabla 3. Estilo de vida: la importancia del espacio verde en el hogar y en el vecindario (\%)

\begin{tabular}{|c|c|c|c|c|c|}
\hline & 1 & 2 & 3 & 4 & 5 \\
\hline Encuentro muy agradable que haya parques y jardines públicos en mi barrio & 1,71 & 0,80 & 3,41 & 16,55 & 77,53 \\
\hline No me gusta tener un jardín con vegetación exuberante & 22,85 & 8,72 & 21,04 & 21,04 & 26,35 \\
\hline Nunca he querido tener macetas & 66,20 & 15,65 & 10,45 & 1,71 & 6,02 \\
\hline Para mí es muy importante la presencia de plantas en mi hogar & 6,02 & 2,51 & 6,02 & 18,05 & 67,40 \\
\hline
\end{tabular}

1 (completamente en desacuerdo), 2 (en desacuerdo), 3 (neutral), 4 (de acuerdo), 5 (fuertemente de acuerdo).

Fuente: Resultados de las entrevistas. Elaboración propia.

Como se observa en la Tabla 3, se ha analizado si el entrevistado encuentra agradable que haya parques y jardines públicos en su vecindario. El 77,53\% ha declarado que está fuertemente de acuerdo, por lo tanto, la mayoría de la población de estas urbanizaciones afirma que desea la presencia de zonas verdes, aunque sepan que cueste dinero y esfuerzo su mantenimiento. La siguiente pregunta se vincula si al entrevistado no le gusta tener un jardín con vegetación exuberante. En esta cuestión, los resultados están más igualados ya que, por ejemplo, el 22,85\% afirma estar fuertemente en desacuerdo, es decir, que quiere tener un jardín con vegetación exuberante. En cambio, hay un 21,04\% para los que han respondido neutral y están de acuerdo respectivamente, mientras que un 26,35\% han declarado estar fuertemente de acuerdo, es decir que no quieren vegetación exuberante. Estos resultados vienen a reflejar que hay una división de opiniones más o menos similares entre los entrevistados que les gusta tener una vegetación exuberante en su jardín o no, ya que ello supone un gasto en el consumo de agua, y por lo tanto, no estarían dispuestos a tener esta tipo de vegetación. Por ello, con estos resultados se observa la percepción que les supone a la población tener un jardín con vegetación exuberante, que se traduce a su vez en un incremento de la factura del agua al haber una mayor densidad de vegetación y necesidad hídrica (Domene y Saurí, 2006).

En la tercera pregunta, "Nunca he querido tener macetas", los resultados son concluyentes, ya que el 66,20\% ha declarado estar fuertemente en desacuerdo. Es decir, la mayoría de población quiere tener macetas en su hogar. Primero, porque han declarado que les gusta la presencia de zonas verdes, y segundo, porque saben que la vegetación en macetas permite ahorrar más agua y tenerlas, por ejemplo, en zonas pavimentadas, estrategia reciente llevada a cabo en las áreas verdes privadas de la costa de Alicante (Morote y Hernández, 2014). Siguiendo la lógica de los resultados anteriores, la cuestión relacionada si para el entrevistado es importante la presencia de plantas en su hogar, vienen a reflejar datos similares. Por ello, el $67,40 \%$ de los entrevistados ha afirmado que está fuertemente de acuerdo en que es importante la presencia de éstas en su hogar, que viene a reflejar a su vez los datos anteriores de la presencia de macetas.

\subsubsection{La recreación en el jardín: la importancia del jardín como una fuente de ocio y de entretenimiento}

En este subapartado se han reflejado los resultados obtenidos en relación con la satisfacción que les proporciona a los entrevistados dedicarse al jardín, ya que con ellos se puede analizar si realmente quie- 
ren tener zonas verdes en su hogar, aunque sepan que ello va a suponer un gasto en el consumo de agua, mayor coste de mantenimiento y dedicación de parte de su tiempo libre; pero en contrapartida es un elemento importante que favorece la sociabilidad de las personas (Larsen y Harlan, 2006).

En la primera pregunta, "Me proporciona gran satisfacción dedicarme al jardín", la mayoría ha declarado estar fuertemente de acuerdo (el 46,54\%) en contra de los que han afirmado estar fuertemente en desacuerdo (el 11,41\%) (Tabla 4). Por lo tanto, la mayoría de la población, aparte de querer tener zonas verdes en su hogar, también le produce satisfacción dedicarse a él. También porque la mayoría de esta población son jubilados, y por lo tanto tienen tiempo para dedicarse a ellos, además por la tradición de la jardinería de los países anglosajones. La siguiente pregunta está relacionada con la percepción que tiene el entrevistado si dedicarse a la jardinería es una pérdida de tiempo. Los resultados han sido paralelos a la pregunta anterior, ya que no sólo les satisface dedicarse a ellos, si no que consideran que no es una pérdida de tiempo. En este sentido, el 73,48\% ha declarado estar fuertemente en desacuerdo.

Tabla 4. La recreación en el jardín: la importancia del jardín como una fuente de ocio y de entretenimiento (\%)

\begin{tabular}{|c|c|c|c|c|c|}
\hline & 1 & 2 & 3 & 4 & 5 \\
\hline Me proporciona gran satisfacción dedicarme al jardín & 11,41 & 6,15 & 15,71 & 20,19 & 46,54 \\
\hline La jardinería es una pérdida de tiempo & 73,48 & 11,51 & 8,81 & 0,00 & 6,19 \\
\hline Cuidar mi jardín es una manera agradable de romper con mi rutina & 15,76 & 3,51 & 13,05 & 21,08 & 46,59 \\
\hline No me gusta la jardinería & 72,62 & 4,51 & 7,32 & 5,52 & 10,03 \\
\hline
\end{tabular}

1 (completamente en desacuerdo), 2 (en desacuerdo), 3 (neutral), 4 (de acuerdo), 5 (fuertemente de acuerdo).

Fuente: Resultados de las entrevistas. Elaboración propia.

En la tercera pregunta, "Cuidar mi jardín es una manera agradable de romper con mi rutina", los datos son similares a las cuestiones sobre si la jardinería es una pérdida de tiempo o si les satisface dedicarse al jardín, ya que el 46,59\% ha afirmado estar fuertemente de acuerdo y el 21,08\% de acuerdo. En cambio, fuertemente en desacuerdo están sólo el 15,76\%. Por lo tanto, hay una mayoría de población que ve positivo tener un jardín, ya que le ayuda a romper con la rutina diaria. Lo mismo ocurre con los resultados relacionados con la pregunta si al entrevistado no le gusta la jardinería, ya que como era lógico pensar, viendo los anteriores resultados, la mayoría está fuertemente en desacuerdo en que no le gusta la jardinería, en concreto el $72,62 \%$. Estos datos vienen a justificar todo lo comentado anteriormente, ya que si al entrevistado le satisface tener un jardín, éste afirma que dedicarse a él, no es una pérdida de tiempo y además, le ayuda romper con la rutina, por lo tanto, es lógico pensar que les guste tener un jardín.

\subsubsection{Interés en el jardín: el disfrute de la jardinería como una actividad}

En este subapartado se ha querido hacer mención al uso y disfrute que dan los entrevistados al jardín. Se han elaborado diferentes preguntas referentes si al entrevistado le gusta enseñar el jardín a sus amigos o familiares, si pasa buenos ratos en él, si los que habitan en la vivienda hacen uso de él o si la parte exterior de la vivienda es un lugar idóneo para realizar comidas o cenas. En definitiva, datos que viene a reflejar si realmente el jardín está cuidado (se riega y se le dedica tiempo) y si lo utilizan como área de recreo y descanso y que además, facilita asimismo las relaciones interpersonales.

Tabla 5. Interés en el jardín: el disfrute de la jardinería como una actividad (\%)

\begin{tabular}{|c|c|c|c|c|c|}
\hline & 1 & 2 & 3 & 4 & 5 \\
\hline Me gusta enseñar mi jardín a mis amigos y familiares & 10,85 & 5,37 & 22,62 & 14,98 & 46,18 \\
\hline Paso buenos ratos en mi jardín & 5,31 & 2,61 & 9,72 & 17,64 & 64,73 \\
\hline Los que viven en esta casa nunca hacen uso del jardín & 66,13 & 11,62 & 4,41 & 6,21 & 11,62 \\
\hline La parte exterior de la vivienda es un lugar ideal para hacer cenas o comidas & 11,63 & 0,00 & 5,32 & 15,05 & 67,80 \\
\hline
\end{tabular}

1 (completamente en desacuerdo), 2 (en desacuerdo), 3 (neutral), 4 (de acuerdo), 5 (fuertemente de acuerdo).

Fuente: Resultados de las entrevistas. Elaboración propia.

En la primera pregunta, "Me gusta enseñar mi jardín a mis amigos y familiares", el 46,18\% ha declarado que está fuertemente de acuerdo en enseñarlo, el 14,98\% de acuerdo, el 22,62\% neutral, el 5,37\% en 
desacuerdo y el 10,85\% fuertemente en desacuerdo (Tabla 5). Esto indica que la gran mayoría de las personas entrevistadas presume del jardín, lo cuida y riega, y por lo tanto, serán jardines que en un principio demandarán una gran cantidad de agua, dependiendo también de los elementos presentes como, césped, plantas crasas, etc., o al menos, tienen plantas que aunque requieran menos cuidado o menos dotación hídrica, generan una imagen positiva del espacio ajardinado. También se les preguntó si pasaban buenos ratos en su jardín. Los datos también son concluyentes, ya que el 64,73\% afirmó que está fuertemente de acuerdo, el $17,64 \%$ está de acuerdo, el 9,72\% neutral, el 2,61\% en desacuerdo y el 5,31\% fuertemente en desacuerdo.

En relación si los que viven en la vivienda nunca hacen uso del jardín, entendido éste como la parte externa del hogar, los datos han confirmado que el $66,13 \%$ de los entrevistados están fuertemente en desacuerdo. Es decir, la mayoría de las familias de los entrevistados hacen uso de él como, por ejemplo, usar la piscina, regar o cuidar el jardín, tomar el sol, tiempo de ocio, comidas, etc. La última pregunta de este subapartado se vincula si la parte exterior de la vivienda es un lugar ideal para hacer cenas o comidas. Siguiendo con la lógica de los resultados anteriores, el 67,80\% está fuertemente de acuerdo en que la parte exterior de sus hogares son lugares ideales para estos usos, mientras que sólo el 11,63\% está fuertemente en desacuerdo. Por lo tanto, si son zonas donde la población utiliza el jardín para comer o cenar, ya está indicando que son lugares limpios y acondicionados para disfrutar de estas actividades, como puede ser un jardín limpio, porches o áreas destinadas para el recreo, juego de los niños, etc.

\subsubsection{Actitudes en torno al ahorro y uso del agua}

Uno de los resultados a poner de manifiesto en esta investigación está relacionado con las prácticas y actitudes en torno al ahorro del agua. Por ello, se han realizado diferentes preguntas al entrevistado de si ahorrar agua requiere un esfuerzo que no merece la pena, si el agua del grifo es un recurso demasiado valioso para ser desperdiciado, si el entrevistado cambiaría su estilo de vida por ahorrar un poco más de agua o si ahorrar agua es un deber que se debería cumplir incluso cuando no se está en situación de sequía. Antes de analizar estos resultados, cabe destacar que las respuestas han sido políticamente correctas, ya que la gente cuando contesta a este tipo de preguntas comprometidas, intentan responder positivamente, pero luego, en realidad, aunque estén sensibilizados en ahorrar agua, la mayoría puede seguir haciendo un uso poco eficiente de éste.

Tabla 6. Actitudes en torno al ahorro y uso del agua (\%)

\begin{tabular}{|c|c|c|c|c|c|}
\hline & 1 & 2 & 3 & 4 & 5 \\
\hline Ahorrar agua requiere un esfuerzo que no merece la pena & 82,41 & 7,94 & 0,00 & 0,80 & 8,84 \\
\hline No cambiaría mi estilo de vida por ahorrar algo de agua & 50,45 & 22,52 & 18,92 & 3,60 & 4,50 \\
\hline
\end{tabular}

1 (completamente en desacuerdo), 2 (en desacuerdo), 3 (neutral), 4 (de acuerdo), 5 (fuertemente de acuerdo).

Fuente: Resultados de las entrevistas. Elaboración propia.

En la primera pregunta, "Ahorrar agua requiere un esfuerzo que no merece la pena", el 82,41\% afirmó estar fuertemente en desacuerdo, ya que los entrevistados saben que tener un jardín o una piscina requiere un volumen importante de consumo de agua (Tabla 6). En este sentido, saben que si intentan ahorrar agua en la medida de lo posible, el gasto en la factura del precio del agua será menor. La siguiente pregunta se vincula si el agua del grifo es un recurso demasiado valioso para ser desperdiciado (Figura 4). Los datos han sido similares a los de la pregunta anterior ya que el $87,59 \%$ ha contestado que está fuertemente de acuerdo. En realidad, como se ha destacado anteriormente, son respuestas políticamente correctas, ya que la gente, de manera general, puede pensar que el agua del grifo no debe desperdiciarse, pero en la vida cotidiana son muchos las personas que despilfarran agua, aunque cabe indicar que poco a poco hay población más concienciada con el ahorro de agua (March, Domènech y Saurí, 2013). Numerosos son los trabajos relacionados con la concienciación ambiental (Yabiku, et al., 2008; Larson, Casagrande, Harlan y Yabiku, 2009; Kiesling y Manning, 2010). Otros trabajos tienen que ver con las campañas ambientales a favor del ahorro de recursos hídricos (Savenije y Van der Zaag, 2002; Randolph y Troy, 2008). Por ejemplo, estos últimos autores, analizaron para la ciudad de Sydney (Australia) que las estrategias de reducción de la demanda de agua y la realización de campañas ambientales han tenido cierto éxito en la reducción del consumo de agua doméstico. 
Figura 4. El agua del grifo es un recurso demasiado valioso para ser desperdiciado

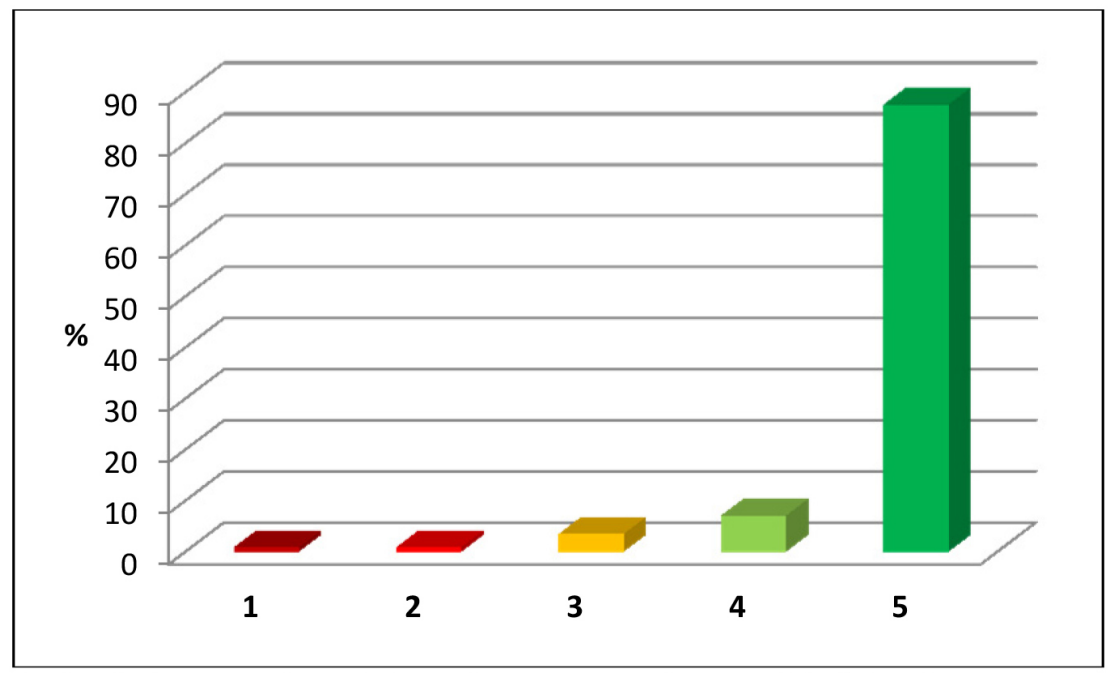

1 (completamente en desacuerdo), 2 (en desacuerdo), 3 (neutral), 4 (de acuerdo), 5 (fuertemente de acuerdo). Fuente: Resultados de las entrevistas. Elaboración propia.

En la tercera pregunta, "No cambiaría mi estilo de vida por ahorrar algo de agua", el 50,45\% ha contestado que está fuertemente en desacuerdo, el $22,52 \%$ en desacuerdo y el $18,92 \%$ neutral. Por lo tanto la percepción de la mayoría de los entrevistados ha sido que estarían dispuestos a cambiar su estilo de vida con tal de ahorrar agua. La última pregunta en relación con la percepción sobre el ahorro de agua, se relaciona con si ahorrar agua debería ser un deber incluso cuando no se está en situación de sequía (Figura 5). La gente suele gastar menos agua si se está en situación de sequía (Castillo, López, Marchena y Pedregal, 2013), especialmente cuando les afecta si hay restricciones o por el incremento de la factura. Los resultados han sido que el $85,16 \%$ ha contestado estar fuertemente de acuerdo en que ahorrar agua es un deber que se tiene que cumplir incluso cuando no se está en periodo de escasez hídrica. Esta variable permite ver si las sequías, o la posibilidad de éstas que se den el futuro, producen una mayor sensibilización en la población respecto al consumo de agua. En este sentido, en algunos estudios, las sequías provocaron cambios en la actitud de los residentes en su apreciación del valor del agua que influiría, a su vez, en un mayor nivel de responsabilidad en el futuro (Aini, Fakhru'l-Razo y Siew, 2001).

Figura 5. Ahorrar agua es un deber que se tiene que cumplir incluso cuando no se está en situación de sequía

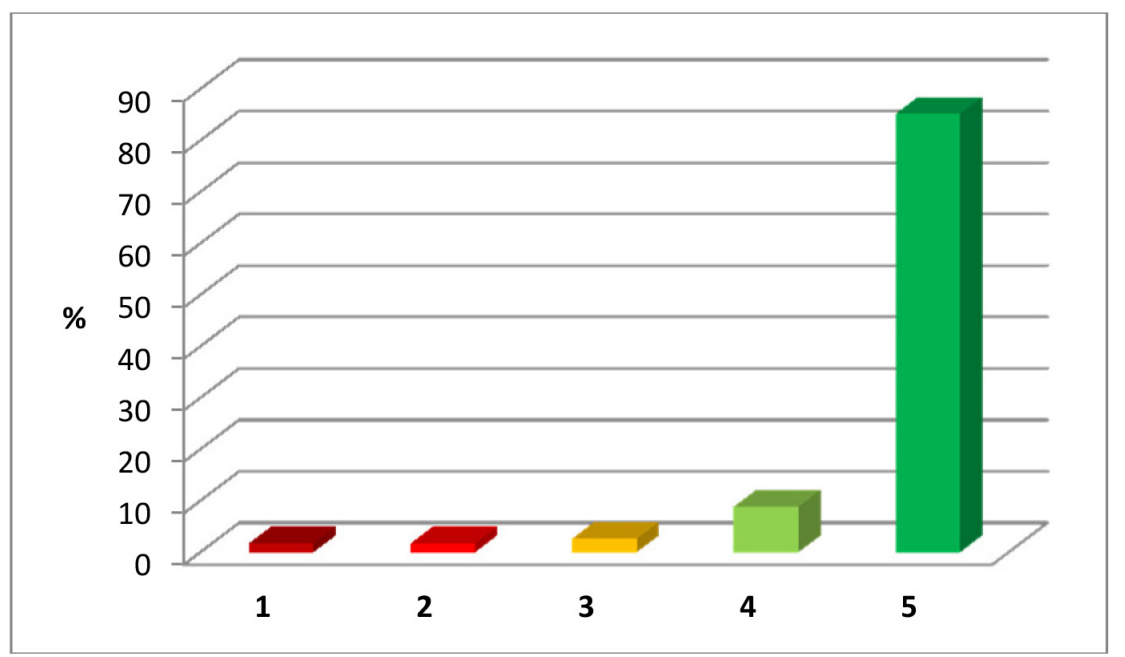

1 (completamente en desacuerdo), 2 (en desacuerdo), 3 (neutral), 4 (de acuerdo), 5 (fuertemente de acuerdo) Fuente: Resultados de las entrevistas. Elaboración propia. 


\subsubsection{Hábitos de los usos del agua en el hogar, tanto en el interior como en el exterior del hogar}

En este subapartado se ha hecho referencia a las medidas adoptadas por parte de los entrevistados para ahorrar agua en su vivienda. Entre las diferentes preguntas que se han realizado se encuentran las relacionadas si el entrevistado tiene en cuenta el tipo de planta que va a ubicar en su jardín en función de su necesidad hídrica, si malgasta agua del grifo, por ejemplo, cuando se ducha o el horario de riego de las plantas, es decir, si lo hace a una hora cuando la evapotranspiración es menor y por tanto mayor es la eficiencia en el riego. Por otro lado, también se ha mencionado el modo de utilización de determinados electrodomésticos que usan agua como es el caso de la lavadora.

En la primera pregunta "Cuando debo comprar plantas para mi jardín, siempre tengo en cuenta que no se tengan que regar mucho", la mayoría ha afirmado estar fuertemente de acuerdo con un $51 \%$, mientras que en neutral ha respondido el 31,26\% (Tabla 7). En un principio, como se observa en estos resultados, la mayoría coincide en que si compra un tipo determinado de vegetación, como plantas crasas, va ahorrar más agua que si instala, por ejemplo, césped. La siguiente pregunta se vincula si cuando el entrevistado se ducha, cierra el grifo mientras se enjabona. La mayoría de ellos ha respondido positivamente (el $58,25 \%$ ha contestado que está fuertemente de acuerdo). En este sentido, cabe indicar que esta acción puede representar hasta 1.015 litros por hora, la mitad si se usan economizadores (Aquareturn, 2015).

Una de las preguntas en las que se puede analizar si realmente el entrevistado está concienciado con el ahorro de agua es si riega las plantas a primera hora de la mañana o última de la noche. Es decir, si se riega a una determinada hora cuando el calor no es elevado ni el sol está en su cenit, con lo que el agua del riego es mucho más eficiente y de esta manera no se evapora con tanta facilidad. Por ejemplo, regar los jardines de 8 a 12 horas de la tarde-noche y de 4 a 8 de la mañana resulta más eficiente debido a que la evaporación es baja o nula, la presión de la red es alta, la dispersión provocada por el viento es baja y las pérdidas por evaporación son despreciables (Manco, Guerrero y Ocampo, 2012). Así pues, el 53,64\% ha declarado regar las plantas a primera hora de la mañana o última de la noche, pero por otro lado también destaca que el $27,81 \%$ ha afirmado estar en desacuerdo. Por lo tanto, la mayoría riega a unas horas más propicias para el ahorro de agua, pero hay una notable presencia de entrevistados que no lo hacen a esa hora, con lo que el consumo de agua, en parte, aumentará en estos hogares por la mala praxis del riego.

Tabla 7. Hábitos en los usos del agua en el hogar, tanto en el interior como en el exterior (\%)

\begin{tabular}{|c|c|c|c|c|c|}
\hline & 1 & 2 & 3 & 4 & 5 \\
\hline $\begin{array}{l}\text { Cuando debo comprar plantas para mi jardín, siempre tengo en cuenta que no } \\
\text { se tengan que regar mucho }\end{array}$ & 3,51 & 0,80 & 31,26 & 13,43 & 51,00 \\
\hline Cuando me ducho cierro el grifo mientras me enjabono & 10,62 & 3,51 & 17,64 & 9,72 & 58,52 \\
\hline Riego las plantas a primera hora de la mañana o a última de la noche & 0,00 & 27,81 & 7,95 & 10,62 & 53,64 \\
\hline A menudo utilizo la lavadora cuando no está llena & 54,45 & 11,41 & 20,12 & 7,01 & 7,01 \\
\hline
\end{tabular}

1 (completamente en desacuerdo), 2 (en desacuerdo), 3 (neutral), 4 (de acuerdo), 5 (fuertemente de acuerdo).

Fuente: Resultados de las entrevistas.Elaboración propia.

La última pregunta del cuestionario finalizaba con el uso eficiente de la lavadora. En este caso, la pregunta era si el entrevistado a menudo utilizaba la lavadora cuando no está llena. Los resultados han sido que el 54,45\% ha declarado que está fuertemente en desacuerdo. Por lo tanto, la mayoría de las personas que han sido entrevistadas han citado que realizan un uso eficiente de éste electrodoméstico, que se caracteriza por el consumo excesivo de agua; si bien en los últimos años se ha generalizado el uso de electrodomésticos de eficiencia en el consumo de agua, así como los programas cortos o con media carga. Desde principios del 2000 han sido notorios los avances en el ahorro de agua en esta teconología. En este sentido, cabe destacar la incorporación de programas "eco", programas de lavado corto o la difusión de las etiquetas de eficiencia energética en los electrodomésticos (Norma EU no 1059/2010). Ello ha supuesto un ahorro en torno al $40 \%$ de los consumos de agua y luz generados. En la actualidad, todas las marcas de electrodomésticos que se comercializan en España ofertan modelos dentro de la categoría de clase energética "A". También cabe indicar que la disminución del precio de estos productos ha permitido su generalización en los hogares (Albiol y Agulló, 2014). Por ejemplo, en las gamas altas de estos productos, el consumo de agua en lavadoras y lavavajillas con la etiqueta "A+++" se sitúa en horquillas que, según marcas y modelos oscilan entre 7 y 10 litros en los lavavajillas y entre 10 y 12 litros en las 
lavadoras por ciclo de lavado. Teniendo en cuenta que el consumo de estos aparatos generan alrededor del 20\% del consumo doméstico y que el 90 y el 50\% de los hogares disponen de lavadoras y lavavajillas respectivamente, se determina que los consumos generados por las lavadoras sean superiores a los de lavavajillas (Gil, et al., 2015).

\section{DISCUSIÓN}

Las medidas adoptadas por los residentes de las viviendas de las urbanizaciones del litoral de Alicante han sido producidas por una serie de causas como son el incremento del precio del agua en los últimos años, la posible pérdida de renta económica en relación con la actual crisis económica, el coste y tiempo en mantener los espacios ajardinados, la escasez de precipitaciones debido a los últimos y recurrentes episodios de sequías y un incremento de la concienciación ambiental. En este sentido, no hay que olvidar que la mayoría de la población entrevistada es población cualificada, con un poder adquisitivo medio-alto y personas mayores, que según la literatura científica al respecto, son más proclives al ahorro de agua que la población joven (Lyman (1992). En vinculación con lo anterior, en un estudio en el mediterráneo español llevado a cabo por Gil, et al., (2015), se puso de manifiesto que una persona de 65 años o más puede llegar a consumir un 25\% menos de agua que la población joven. Estudios como el de Gregory y Di Leo (2003) en Shoalhaven (Australia) y el de Gilg y Barr (2006) en Devon (sur-oeste de Inglaterra) siguen esta misma línea argumental, es decir, los residentes con mayor edad muestran unos hábitos de consumo más favorables al ahorro de agua. Sin embargo, otros trabajos han mostrado que en los chalés donde residen personas mayores, el consumo de agua aumenta debido a la afición por el riego del jardín (Lyman (1992). Ello se debe por la afición a la jardinería, tan arraigada, por ejemplo, en el mundo anglosajón. También se encuentran estudios con resultados diferentes a los anteriores. Mayer, et al., (1999), en una investigación llevada a cabo en un conjunto de ciudades norteamericanas (Denver, San Diego, Tampa, etc.), argumentan que la población joven, concretamente los niños, consumen menos agua del grifo que adolescentes y adultos.

La mayoría de los entrevistados están a favor de la presencia de zonas verdes en su vivienda y afirman que es importante la presencia de estas áreas debido a que se concibe como un espacio de socialización y recreo. Numerosas son las investigaciones que se dedican al análisis de estos factores (Bhatti y Andrew, 2004; Syme, Shao, Po y Campebell, 2004; Larsen y Harlan, 2006). Estos últimos, investigaron específicamente el uso de agua en el exterior de la vivienda para el caso de la ciudad de Perth (Australia), llegando a la conclusión de que el estilo de vida (ocio y recreación del jardín) repercute en el incremento del consumo de agua, principalmente para los elementos exteriores de la vivienda (jardín y piscina). El jardín como elemento externo permite evidenciar fácilmente el estatus social, entendido en términos de nivel de ingresos de sus propietarios. También es importante destacar que la mayoría ha respondido que están a favor de la instalación de la vegetación en macetas, ya que de esta manera se consigue ahorrar agua en el riego y coste y duración en mantenerlo.

La mayoría de los entrevistados también ha puesto de manifiesto que les gusta dedicarse al jardín. En este sentido, cabe recordar que el 75\% era población extranjera (el 40,54\% del Reino Unido) y personas de más 60 años o más (jubilados), es decir, en teoría con tiempo libre para practicar la jardinería. Además, argumentan que la jardinería no es una pérdida de tiempo y que les ayuda a romper con la rutina diaria. En relación con el uso del jardín, la mayoría ha respondido que le gusta enseñarlo, que pasa buenos ratos y que es una zona ideal para celebrar cenas y reuniones. Por lo tanto, estos resultados ponen de manifiesto que estos espacios deben estar cuidados ya que se suele hacer un uso de él, y sobre todo porque es concebido como un lugar de esparcimiento y de ocio, especialmente, teniendo en cuenta las buenas condiciones climáticas que goza la costa de Alicante durante todo el año que invita a disfrutar del buen tiempo fuera del hogar. En vinculación con las respuestas en torno al ahorro de agua, la mayoría ha argumentado que práctica medidas a favor del ahorro de agua y consideran que éstas, no son una pérdida de tiempo. Incluso han argumentado que se debería ahorrar sin estar en situaciones de sequía. También, la mayoría ha afirmado que tienen en cuenta el tipo de vegetación a la hora de su elección (en función de la necesidad hídrica), al igual que la práctica de riego a unas horas adecuadas del día.

Por lo tanto, uno de los cambios ha sido un comportamiento a favor del ahorro de agua motivado por un incremento de la concienciación ambiental donde las administraciones y empresas encargadas del suministro de agua han jugado un papel clave con la difusión de campañas de sensibilización ambiental 
(Figura 6). Por ejemplo, en Zaragoza entre los años 1997 y 1999 se llevó a cabo el proyecto "Zaragoza, ciudad ahorradora de agua. Pequeños pasos, grandes soluciones", que repercutió que después de un año de implementación, se consiguiera ahorrar 1.176 millones de litros de agua (el 5,6\% del consumo doméstico anual). Al finalizar dicho proyecto, se identificó que el número de familias que adoptaron hábitos de ahorro de agua pasó de $20 \%$ a $50 \%$ y el número de familias que introdujeron tecnologías eficientes pasó del 13\% al 15\% (Fernández y Viñuales, 1999). También para la ciudad de Zaragoza, Barberán y Salvador (2010), calcularon una reducción de 13,24 1/hab./día después de la intervención a partir de información y sensibilización. En California (EE.UU.), Renwick y Green (2000), llevaron a cabo un estudio en el que se evaluaron programas de ahorro de agua y sus efectos en el consumo de agua residencial, y en relación con las campañas de información pública, el porcentaje de reducción de agua calculado fue del 8\%. Un papel crucial han tenido también los episodios de escasez de precipitaciones. Por ejemplo, en el sur de España (Sevilla), la sequía de 1999-2000 tuvo un efecto inicial en la reducción del consumo de agua de un 2,9\% (Castillo, et al., 2013).

Figura 6. Campañas divulgativas para fomentar el ahorro de agua llevadas a cabo por Aguas Municipalizadas de Alicante, Empresa Mixta S.A. Imagen izquierda (Gotagotham: Campaña educativa para escolares de primaria). Imagen derecha("Agua de confianza" (2010: Campaña de comunicación a través de anuncios gráficos)
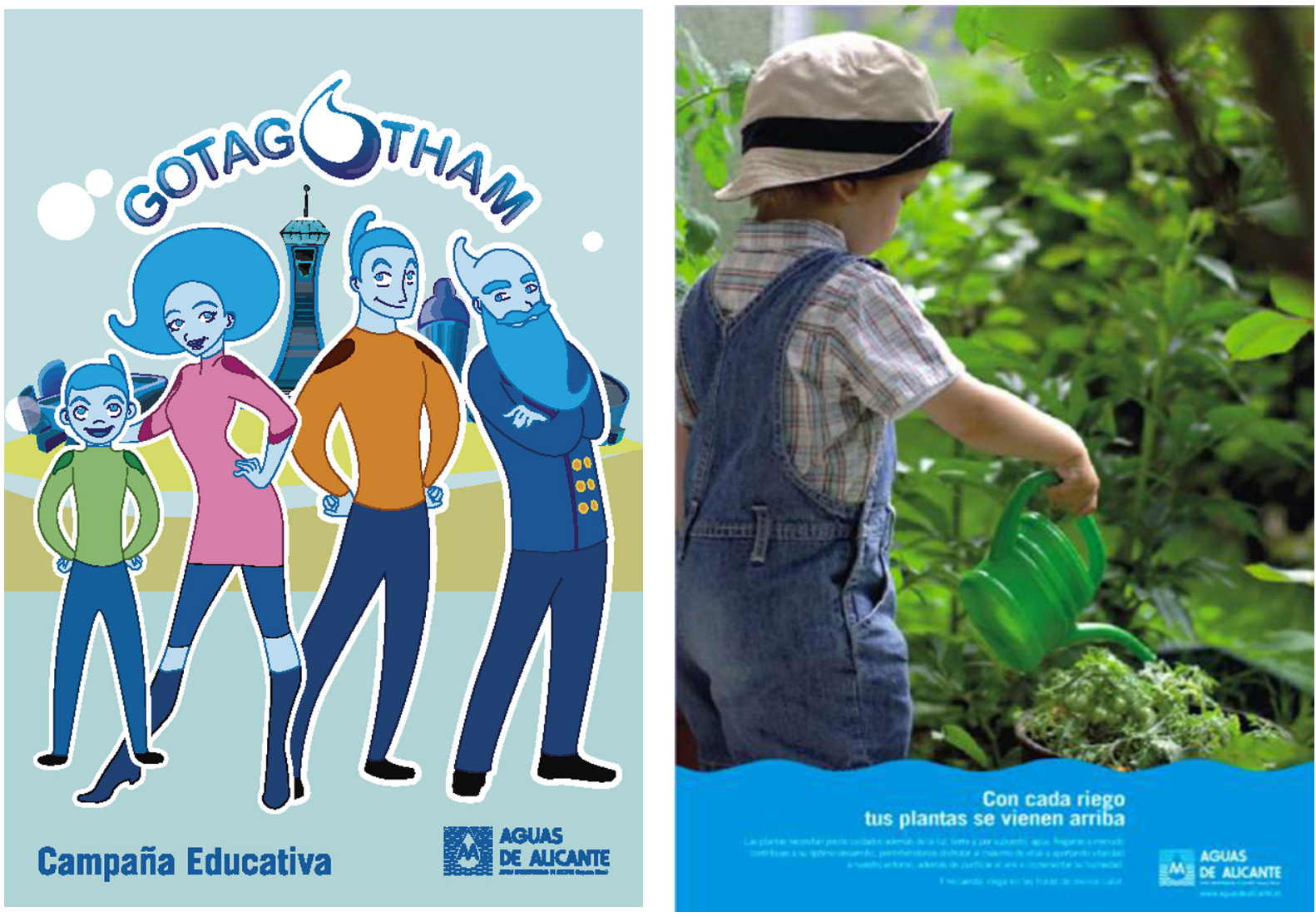

Fuente: Aguas Municipalizadas de Alicante, Empresa Mixta S.A.

En relación con las modificaciones en los espacios ajardinados, Wentz y Gober (2007) demostraron en un estudio llevado a cabo en la ciudad de Phoenix (Arizona) que la población que se asienta en un territorio, implantan el mismo tipo de jardinería de su país de origen. En cambio, Morote y Hernández (2014) comprobaron cómo la población extranjera procedente del norte y centro de Europa que reside en las urbanizaciones alicantinas, han modificado los patrones de ajardinamiento con tal de ahorrar agua para el riego del jardín. Algunas de las múltiples estrategias han sido sustituir el césped por plantas mediterráneas o áreas pavimentadas o incluso sustituirlo por césped artificial. En este sentido, la utilización de este último en el paisajismo urbano (público y privado) es cada día más frecuente en las ciudades españolas, sobre todo en las regiones caracterizadas por la insuficiencia hídrica. Así lo han hecho ya numerosos ayuntamientos de Murcia, Comunidad Valenciana, Baleares o Comunidad de Madrid. Entre ellos destaca 
el de la ciudad de Parla, que ha utilizado césped artificial para ornamentar su nueva línea de tranvía, o el de Madrid, que lo emplea en rotondas, medianas y zonas verdes. Otro de los terrenos en los que el césped artificial resulta provechoso es en la denominada "xerojardinería", un modelo de jardín en el que se utilizan diferentes técnicas para garantizar un consumo racional de agua, evitando su evaporación (Burés, 1991). Esta práctica, cada vez más extendida en España y Europa, es una nueva herramienta para el desarrollo sostenible del territorio y se caracteriza por utilizar especies con uso ornamental que requieren poco agua para su mantenimiento (Construnario, 2015).

Teniendo en cuenta que las personas entrevistadas son población con una renta media y media-alta, hay autores que afirman que en los hogares donde se dan los mayores ingresos económicos, se produce un menor consumo de agua debido a una mayor concienciación ambiental, y en consecuencia, a favor del ahorro del agua. Cabe mencionar el estudio de Flack y Greenberg (1987), quienes estudiaron este factor en el Estado de Colorado (EE.UU.). En su investigación, llevaron a cabo encuestas en siete comunidades del noreste de este estado para determinar si existen relaciones entre la concienciación ambiental y las variables socio-económicas. También, estudios como el de Proshanky, Fabian y Kaminoff, (1983) llevado a cabo en EE.UU., argumentan que los residentes que sienten un arraigo especial con el lugar donde viven tienen unos comportamientos pro-ambientales, es decir, tienen una mayor concienciación ambiental, incluso la vegetación que hay presente en sus jardines suele ser autóctona, y por lo tanto, la más adaptada al medio y menos consumidora de agua. También cabe mencionar que una mayor renta disponible por parte de las economías domésticas puede llevar implícito un acceso de estos hogares a nuevos bienes, desde griferías a electrodomésticos, que junto a un mejor diseño o prestaciones, llevan aparejado un consumo cada vez más eficiente de electricidad y agua, repercutiendo en un consumo final de agua dentro del hogar. De esta opinión son Campbell, Jhonson y Larson, (2004), que consideran que ahorrar agua supone tener que invertir dinero en reparaciones o dispositivos de ahorro.

El incremento del precio del agua ha sido otra de las principales causas que ha provocado un cambio de percepción de la población en el ahorro y uso de agua. Esta variable ha sido objeto de atención en numerosas publicaciones (Thomas y Syme, 1988; Renwik y Archibald, 1998; Dalhuisen, Florax, De Groot y Nijkamp, 2003). Hay autores que argumentan que las tarifas y el precio del agua son considerados ambos como una herramienta de control del consumo (Arbués, García y Martínez, 2003; Sánchez y Blanco, 2012). En el estudio de Renwik y Archibald (1998), llevado a cabo en California, los autores llegaron a la conclusión de que un incremento del precio del recurso hídrico repercutía en un descenso del consumo, especialmente en los hogares con las rentas más bajas. Dicho consumo, al responder al nivel de renta y, con ello, a la calidad de la vivienda, dotaciones sanitarias de la misma, espacios verdes, piscina y otras posibles instalaciones acordes con el poder adquisitivo del titular de aquélla, es un indicador digno de la mayor atención para un mejor conocimiento de la diferenciación social del espacio. En este sentido, en comparación con el litoral mediterráneo español, Gil, et al., (2015), analizaron que una de las posibles causas de ese descenso ha sido la pérdida del nivel de renta, especialmente en las clases medias. Además se pone de manifiesto que esta reducción haya podido resultar más o menos afectada por la actual crisis, así como en qué medida ésta pueda o no haber incidido en el nivel de calidad de vida, en buen número de casos nivel de subsistencia, con la adopción de estrategias o actuaciones para reducir o, en determinados supuestos, rebajar o evitar fraudulentamente el recibo de agua.

\section{CONCLUSIONES}

Algunas de las principales conclusiones extraídas de la presente investigación han sido las numerosas estrategias y cambios llevados a cabo por los propietarios de las viviendas con tal de ahorrar agua para los usos del jardín en los últimos años. Estos cambios han sido la instalación de vegetación en macetas y la adopción de medidas y dispositivos de ahorro instalados para fomentar el ahorro de agua, entre otros. La mayoría de los entrevistados está a favor de la presencia de áreas ajardinadas en sus viviendas y en su vecindario, aunque son conscientes de que ello implica un mayor coste económico para su mantenimiento. Por ello, como se ha puesto de manifiesto, la instalación de macetas en zonas pavimentadas y la elección de especies vegetales autóctonas y con escasa necesidad hídrica, es una de las medidas adoptadas por estos residentes. Ello, en parte, se debe al incremento del precio del agua y la frecuencia de episodios de sequías en los últimos años. Todo ello hay que relacionarlo dentro de un marco de crisis económica actual y de escasez de recursos hídricos debido a los recurrentes episodios de sequía en el sureste español. 
Los espacios ajardinados de estos residentes, como demuestran los resultados, es un lugar de socialización y de ocio. No cabe olvidar que el 40,54\% de los entrevistados son de nacionalidad británica donde la jardinería es una de las costumbres domésticas más arraigadas. Como describen Morote y Hernández (2014) uno de los cambios llevados a cabo en los jardines privados del litoral alicantino ha sido la reducción de la superficie de césped, la pavimentación de las áreas ajardinadas, la instalación de vegetación en macetas o incluso la instalación de césped artificial. En este sentido, el césped natural es uno de los grandes consumidores de agua en la actualidad y requiere un mantenimiento frecuente e intenso. Por ello, la hierba artificial constituye una alternativa segura y eficaz para reducir el consumo de este recurso limitado, como así lo han considerado un gran número de ayuntamientos, propietarios de jardines, empresas y entidades deportivas que han apostado en los últimos tiempos en España por esta variante ecológica. Una tendencia que viene respaldada por el criterio de numerosos expertos ambientales y de estudios contrastados. Se estima una cantidad entre 780 y 917 litros/año/ $\mathrm{m}^{2}$ que se ahorra con la sustitución del césped natural por el artificial en las zonas verdes públicas y privadas, según un estudio realizado en el sur del estado de California por el Irving Ranch Water District (organismo público de suministro de agua). En este territorio de Estados Unidos, con condiciones climáticas similares a las del sureste español, es patente igualmente la preocupación por la escasez del recurso hídrico y por ello, las políticas públicas han destinado cuantiosas subvenciones para promover la implantación del manto artificial en los jardines domésticos y espacios urbanos (Construnario, 2015). Entre estas medidas también se incluiría la introducción de dispositivos de ahorro de agua, nuevas modalidades de captación de aguas, como pueden ser el uso de depósitos de pluviales, etc. (Dalhuisen, et al., 2003; Gaudin, 2006).

Las características de las condiciones climáticas de la costa alicantina, en especial, la escasez de precipitaciones y las secuencias de sequías en los últimos años, y el incremento del monto pagado por la factura del agua (un incremento del 77\% en la última década en la ciudad de Alicante) (Gil, et al., 2015), han sido una de las causas que han motivado un cambio de percepción del uso de agua en el exterior de las viviendas. Además, cabe indicar el peso importante que tiene la población extranjera en la costa de Alicante (especialmente la nacionalidad británica), que suele practicar una jardinería de tipo "atlántica", aunque como se ha comprobado, en los últimos años su percepción en relación con la instalación de especies vegetales con importantes necesidades hídricas ha cambiado a favor de otras especies más acordes con el clima del sureste español. Por lo tanto, los resultados de estas entrevistas han puesto de manifiesto que los propietarios de las viviendas de las urbanizaciones del litoral de Alicante han llevado a cabo cambios y estrategias en el uso del agua en el jardín con tal de ahorrar agua e incluso han cambiado en algunas ocasiones su estilo de vida. Por lo tanto, lo que se puede aprender del caso de Alicante y que se puede extender a otros ámbitos con condiciones climáticas y socio-económicas similares es, que factores como el incremento del precio de agua, escasez de precipitaciones y una mayor concienciación ambiental son los elementos principales a la hora de entender los nuevos comportamientos y percepción del consumo de agua de los residentes de las urbanizaciones del área de estudio.

\section{REFERENCIAS}

Aini, M.S., Fakhru'l-Razo, A. \& Siew, K. (2001). Water crisis Management: Satisfaction level, effect and coping of the consumers. Water Resources Management, 15, 31-39.

Albiol, C. y Agulló, F. (2014). La reducción del consumo de agua en España: causas y tendencias. Aquaepapers, Aquae Fundación, 6.

Aquarentum (2015). Consejos para ahorrar agua. Recuperado de https://www.aquareturn.com/blog/ ahorro-agua/26-consejos-para-ahorrar-agua.html. Fecha de consulta 10/06/2015

Arbués, F, García, M.A. y Martínez, R. (2003). Estimation of residential water demand: a state of the art review. Journal of Socio-Economics, 32, 81-102. Doi: http://dx.doi.org/10.1016/S1053-5357(03)00005-2

Askew, L.E. \& MC. Guirk, P.M. (2004). Watering the suburbs: distinction, conformity and the suburban garden. Australian Geographer, 35, 17-37. Doi: http://dx.doi.org/10.1080/0004918024000193702

Barberán, R. y Salvador, M.J. (2010). El uso del agua en los hogares de la ciudad de Zaragoza. Investigación sobre las actitudes, la información, los equipamientos y el comportamiento de los hogares en relación con el uso del agua. Zaragoza: Ayuntamiento de Zaragoza, Centro de Documentación del Agua y el Medio Ambiente. 
Bhatti, M. \& Andrew, C. (2004). Home, the culture of nature and meanings of gardens in late modernity. Housing Studies, 19, 37-51. Doi: http://dx.doi.org/10.1080/0267303042000152168

Burés, S. (1991). El Xeriscape, un nuevo concepto de jardinería. Horticultura, 67, 6-11.

Burriel de Orueta, E. (2008). La década prodigiosa del urbanismo español (1997-2006). Scripta Nova, XII, 270 (64). Recuperado de http://www.ub.es/geocrit/sn/sn-270/sn-270-64.htm

Campbell, H.E., Jhonson, R.M. \& Larson, E.H. (2004). Prices, devices, people or rules: The relative effectiveness of policy instruments in water conservation. Review of policy research, 21, 637-662. Doi: http://dx.doi.org/10.1111/j.1541-1338.2004.00099.x

Casado-Diaz, M.A. (2012). Exploring the geographies of lifestyle mo-bility: current and future fields of enquiry. En Wilson, J. (Ed.), The Routledge Handbook of Tourism Geographies. Routledge, 120-125.

Castillo, J.I., López, L., Marchena, M. y Pedregal, D.J. (2013). La gestión del agua y el uso de contadores individuales en el área metropolitana de Sevilla. En XX Encuentro de Economía Pública. Sevilla, 31 de enero y 1 de febrero de 2013.

Construnario (2015). El césped se hace sostenible. Recuperado de http://www.construnario.com/ notiweb/17787/el-cesped-se-hace-sostenible. Fecha de consulta 10/06/2015

Dalhuisen, J., Florax, R., De Groot, H., \& Nijkamp, P. (2003). Price and income elasticities of residential water demand: a meta-analysis. Land Economics, 79, 292-308.

Del Romero, L. (2008). Planificació i govern del territori a l'arc mediterrani español: Noves i velles respostes en un context globalitzat. Valencia: Publicaciones de la Universidad de Valencia.

Deoreo, W.B. \& Mayer, P.W. (2012). Insights into declining single-family residential water demands. Journal-American Water World Association, 104 (6), 383-394. Doi: http://dx.doi.org/10.5942/ jawwa.2012.104.0080

Domene, E. y Saurí, D. (2006). Urbanization and water consumption. Influencing factors in the Metropolitan Region of Barcelona. Urban Studies, 43(9), 1.605-1.623. Doi: http://dx.doi. org/10.1080/00420980600749969

Fernández, S. y Barrado, D.A. (2011). El desarrollo turístico-inmobiliario de la España mediterránea e insular frente a sus referentes internacionales (Florida y la Costa Azul): un análisis comparado. Cuadernos de Turismo, 27, 373-402.

Fernández, M. y Viñuales, V. (1999). Zaragoza, ciudad ahorradora de agua. 50 buenas prácticas. Fundación Ecología y Desarrollo. Recuperado de http://habitat.aq.upm.es/dubai/06/bp0564.html

Flack, J.E. \& Greenberg, J. (1987). Public attitudes toward water conservation. Journal of the American Water Works Association, 79, 46-51. Doi: http://dx.doi.org/10.1007/s11269-013-0509-7

García Acosta, X. (2013). Urbanització difusa i consum d'aigua per a usos domèstics. Una exploració de relacions. Documents d'Anàlisi Geogràfica, 59/2, 347-362. Doi: http://dx.doi.org/10.5565/rev/dag.42

García Acosta, X. (2014). Jardines privados y consumo de agua en las periferias urbanas de la comarca de la Selva (Girona). Investigaciones Geográficas, 61, 55-69. Doi: http://dx.doi.org/10.14198/ INGEO2014.61.04

Gaudin, S. (2006). Effect of Price information on residential water demand. Applied Economics, 38, 383393. Doi: http://dx.doi.org/10.1080/00036840500397499

Gil Olcina, A., Hernández Hernández, M., Morote Seguido, A.F., Rico Amorós, A.M., Saurí Pujol, D. y March Corbella, H. (2015). Tendencias del consumo de agua potable en la ciudad de Alicante y Área Metropolitana de Barcelona, 2007-2013. Alicante: Hidraqua, Gestión Integral de Aguas de Levante S.A. y la Universidad de Alicante.

Gilg, A. \&Barr, S. (2006). Behavioral attitudes towards water saving? Evidence from a study of environmental actions. Ecological Economics, 57, 400-414. Doi: http://dx.doi.org/10.1016/j.ecolecon.2005.04.010

Gössling, S. (2015). New performance indicators for water management in tourism. Tourism Management, 46, 233-244. Doi: http://dx.doi.org/10.1016/j.tourman.2014.06.018

Gregory, G.D. \& Di Leo, M. (2003). Repeated behavior and environmental psychology: the role of personal involvement and habit formation in explaining water consumption. Journal of Applied Social Psychology, 33, 1.261-1.296. Doi: http://dx.doi.org/10.1111/j.1559-1816.2003.tb01949.x 
Hernández, M. (2013). Análisis de los procesos de transformación territorial en la provincia de Alicante (1985-2011) y su incidencia en el recurso hídrico a través del estudio bibliográfico. Documents d’Anàlisi Geogràfica, 59/1, 105-136.

Hurd, B.H. (2006). Water conservation and residential landscape: household preferences, household choices. Journal of Agricultural and Resource Economics, 31, 21-32.

Kiesling, F.M. \& Manning, C.M. (2010). How green is your thumb? Environmental gardening identity and ecological gardening practices. Journal of Environmental Psychology, 30, 315-327. Doi: http:// dx.doi.org/10.1016/j.jenvp.2010.02.004

Larsen, L. \& Harlan, S.L. (2006). Desert dreamscapes. Residential landscapes preference and behavior. Landscape and Urban Planning, 78, 85-100. Doi: http://dx.doi.org/10.1016/j.landurbplan.2005.06.002

Larson, K.L., Casagrande, D., Harlan, S.L. \& Yabiku, S.T. (2009). Residents yard choices and rationales in a desert city: Social priorities, ecological impacts, and decision tradeoffs. Environmental Management, 44, 921-937. Doi: http://dx.doi.org/10.1007/s00267-009-9353-1

Loh, M. \& Coghlan, P. (2003). Domestic water use study: Perth, Western Australia 1998-2001. Perth: Water Corporation.

Lyman, R.A. (1992). Peak and off-peak residential water demand. Water Resources Research, 28, 2.1592.167. Doi: http://dx.doi.org/10.1029/92WR01082

Manco, D.G., Guerrero, J. y Ocampo, A.M. (2012). Eficiencia en el consumo de agua de uso residencial. Revista Ingenierías Universidad de Medellín, 21, 23-38.

March, H. y Saurí, D. (2014): ¿Qué sostenibilidad hídrica? Una interpretación crítica del descenso reciente del consumo doméstico de agua en Barcelona. Waterlat-Gobocit Network Working papers, 1, 2, 27-43.

March, H., Domènech, L., y Saurí, D. (2013). Water conservation campaigns and citizen perceptions: the drought of 2007-2008 in the Metropolitan Area of Barcelona. Natural Hazards, 65, 1.951-1.966. Doi: http://dx.doi.org/10.1007/s11069-012-0456-2

Mayer, P.W., Deoreo, W.B., Optiz, E., KieferJ., Dziegielewski, B. \& Davis, W. (1999). Residential end uses of water. Denver: American Water Works Association Research Foundation.

Molina, J., Garriga, N., Boada, M., Huelin, S., Martí, X., Domene, E. y Saurí, D. (2004). Estudi del consum d'aigua als edificis de la Regió Metropolitana de Barcelona: Situació actual y possibilitats d'estalvi: Recuperado de http://www.fundacioabertis.org/rcs_est/estudi_complet.pdf

Morote Seguido, A.F. (2014). Tipologías urbano-residenciales del litoral de Alicante: repercusiones territoriales. Ciudad y Territorio. Estudios Territoriales, XLVI, 181, 431-443.

Morote Seguido, A.F. (2015). Transformaciones territoriales e intensificación de la demanda de agua urbanoturística en la provincia de Alicante. Tesis Doctoral, Alicante, Universidad de Alicante.

Morote Seguido, A.F. y Hernández Hernández, M. (2014). Jardines y urbanizaciones, nuevas naturalezas urbanas en el litoral de la provincia de Alicante. Documents d'Anàlisi Geogràfica, 60/3, 483-504. Doi: http://dx.doi.org/10.5565/rev/dag.122

Morote, A.F. \& Hernández, M. (2016). Urban sprawl and its effects on water demand: A case study of Alicante, Spain. Land Use Policy, 50, 352-362. Doi: http://dx.doi.org/10.1016/j.landusepol.2015.06.032

Morote, A.F., Saurí, D. \& Hernández, M. (2016). Residential Tourism, Swimming Pools and Water Demand in the Western Mediterranean. Professional Geographer. Doi: http://dx.doi.org/10.1080/003 $\underline{30124.2015 .1135403}$

Mustafa, D., Smucker, T.A., Ginn, F., Johns, R. \& Connely, S. (2010). Xeriscape people and the cultural politics of turfgrass transformation. Environment and Planning D, 28, 600-617. Doi: http://dx.doi. org/10.1068/d13108

Padullés, J., Vila, J. y Barriocanal, C. (2014a). Maintenance, Modifications, and Water Use in Private Gardens of Alt Empordà, Spain. HortTechnology, 24 (3), 374-383.

Padullés, J., Vila, J. y Barriocanal, C. (2014b). Examining floristic boundaries between garden types at the global scale. Investigaciones Geográficas, 61(1), 71-86. Doi: http://dx.doi.org/10.14198/ INGEO2014.61.05 
Padullés, J., Vila, J. y Barriocanal, C. (2016). Floristic and structural differentiation between gardens of primary and secondary residences in the Costa Brava (Catalonia, Spain). Urban Ecosystems. Doi: http:// dx.doi.org/10.1007/s11252-015-0496

Piqueras, J. (2012). Geografía del territorio valenciano. Naturaleza, economía y paisaje. Valencia: Universidad de Valencia.

Proshanky, H.M., Fabian, A.K. \& Kaminoff, R. (1983). Place identity: Physical world socialization of the self. Journal of Environment Psychology, 3, 57-83. Doi: http://dx.doi.org/10.1016/S0272-4944(83)800021-8

Randolph, B. \& Troy, P. (2008). Attitudes to conservation and water consumption. Environmental Science and Policy, 11 (5), 441-455. Doi: http://dx.doi.org/10.1016/j.envsci.2008.03.003

Renwick, M. \& Archibald, S. (1998). Demand side management policies for residential water use: who bears the conservation burden?. Land Economics, 74, 343-359. Doi: http://dx.doi.org/10.2307/3147117

Renwick, M. \& Green, R. (2000). Do residential water demand side management policies measures up? An analysis of eight California water agencies. Journal of Environmental Economics and Management, 40, 37-55. Doi: http://dx.doi.org/10.1006/jeem.1999.1102

Rico Amorós, A.M. (2007). Tipologías de consumo de agua en abastecimientos urbano-turísticos de la Comunidad Valenciana. Investigaciones Geográficas, 42, 5-34. Doi: http://dx.doi.org/10.14198/ INGEO2007.42.01

Salvati, L. \& Sabbi, A. (2011). Exploring long term land cover changes in an urban region of Southern Europe. International Journal of Sustainable Development and World Ecology, 18(4), 273-282. Doi: http:// dx.doi.org/10.1080/13504509.2011.560453

Sánchez, V.E. y Blanco, FJ. (2012). El uso sostenible del agua en núcleos urbanos: las tarifas como herramienta de control del consumo. Observatorio ambiental, 15, 35-59.

Saurí, D. (2003). Lights and shadows of urban water demand management. The case of the metropolitan region of Barcelona. European Planning Studies, 11, 229-243. Doi: http://dx.doi. org/10.1080/09654310303639

Savenije, H. \& Van der ZAAG, P. (2002). Water as an economic good and demand management, paradigms with pitfalls. Water International, 27, 98-104. Doi: http://dx.doi.org/10.1080/02508060208686982

Syme, G.J., Shao, Q., Po, M. \& Campebell, E. (2004). Predicting and understanding home garden water use. Landscape and Urban Planning, 68, 121-128. Doi: http://dx.doi.org/10.1016/j.landurbplan.2003.08.002

Thomas, F. \& Syme, G. (1988). Estimating residential price elasticity of demand for water; a contingent valuation approach. Water Resources Research, 24, 1.847-1.857. Doi: http://dx.doi.org/10.1029/ WR024i011p01847

Troy, P. \& Holoway, D. (2004). The use of residential water consumption as an urban planning tool: a pilot study in Adelaide. Journal of Environmental Planning and Management, 47, 97-114. Doi: http://dx.doi. org/10.1080/0964056042000189826

Vera Rebollo, J.F. (2006). Agua y modelos de desarrollo turístico: la necesidad de nuevos criterios para la gestión de los recursos. Boletín de la Asociación de Geógrafos Españoles, 42, 155-178. Recuperado de http://hdl.handle.net/10045/15502

Wentz, E. \& Gober, P. (2007). Determinants of small-area water consumption for the city of Phoenix, Arizona. Water Resources Management, 21, 1.849-1.863. Doi: http://dx.doi.org/10.1007/s11269-0069133-0

Yabiku, S.T., Casagrande, D.G. \& Farley-Metzger, E. (2008). Preferences for landscape choice in a Southwestern desert city. Environment and Behaviour, 40, 382-400. Doi: http://dx.doi. $\underline{\text { org/10.1177/0013916507300359 }}$ 